\title{
Recently-proposed methods and concepts of testing the effects of pesticides on the beneficial mite and insect species: study limitations and implications in IPM
}

\author{
Hiroshi Amano* and Muhammad Haseeb \\ Laboratory of Applied Entomology and Zoology, Faculty of Horticulture, Chiba University, Matsudo, Chiba 271-8510, Japan
}

(Received 10 April 2000; Accepted 8 October 2000)

\begin{abstract}
Pesticides have played a significant role in traditional crop protection during the last five decades. Consequently, high yields have been harvested from treated crops. However, man's eagerness for inventing these much needed chemicals has not allowed for ample establishment of risk reduction measures against their possible adverse effects on non-target organisms. This occurred mostly because crop production was given top priority, and partly because of the poor research and development ( $R \& D$ ) resources in the past. After many years of pesticide use, it is now recognized that application of broad spectrum and non-selective pesticides could pose high risks to beneficial organisms, especially among mite and insect species which usually regulate pest population(s) under natural conditions. Selective pesticides will always be needed in sustainable integrated pest management (IPM) for commercial-crop(s) pests. Pesticide testing methods to determine the effects of pesticides on beneficial mite and insect species are gaining priorities in R \& D because of their vital importance to crop protection. In this review paper we examine pesticide testing methods and their evaluation and interpretation on beneficial mite and insect species. The limitations and implications of pesticide effects in IPM and their future prospects are also discussed.
\end{abstract}

Key words: Beneficials, mite and insect, IPM, pesticide testing, natural enemy

\section{INTRODUCTION}

Beneficial mite and insect species play an indispensable role in controlling various crop(s) pests worldwide. These species are at the center of concerns for the development of sustainable IPM (Integrated Pest Management) and their existence in nature should be protected. When pesticides are applied to control pest(s), care should be taken to ensure that the most important beneficial mite and insect species are not adversely affected (Tabashnik and Croft, 1985; Waage, 1996). Insecticides and acaricides may have both direct and indirect effects on these organisms, but the effects of other pesticides groups (fungicides and herbicides) are usually indirect and are considered less harmful (Samsøe-Petersen, 1990). When these beneficials are allowed to operate undisturbed in the field, less pesticide treatments are needed for pest management. This ultimately has a positive impact on biological control as well as the diversity of useful species. The integration of beneficials with pesticides for IPM relies heavily on the validity of the available information on the effects of pesticides on beneficials (Hull and Beers, 1985; Hassan, $1992,1994)$. Such information is often difficult to obtain, and even when acquired, may not have general applicability in all situations because of differences among crop species, varieties, cropping practices, varying pest control tactics, natural enemy complexes and genotypes (Stevenson and Walters, 1983). Nevertheless, such information is urgently needed for the development of effective and sustainable IPM programs for a number of crops (Poehling, 1989; Midgarden et al., 1997).

Concerning the beneficial mite and insect groups, deleterious effects of pesticides are strongly indicated by the drastic decline in insect fauna on treated crop and it is reasonable to expect that any beneficial species, particularly predators and parasitoids, are likely to be decimated (Lim et al., 1986; Soon, 1990; Sterk, 1993). In the present overview we discuss recently-proposed methods and concepts of testing the effects of pesticides on beneficial mite and insect species. Study limitations and implications in IPM are also included in the review and we believe that this information will be useful for the execution of future work on pesti-

* To whom correspondence should be addressed at: E-mail: amano@midori.h.chiba-u.ac.jp 
cides and beneficial organisms.

\section{CHOICE OF BENEFICIAL SPECIES}

The identification of beneficial mite and insect species is essential before conducting any pesticide tests (Samsøe-Petersen, 1990; Ruberson et al., 1998). There is general agreement that these beneficials should be relevant to the crops on which pesticides are to be used in practice. In this respect, data regarding the importance of the beneficial species for a particular pest on single or related crops should be known. Beneficial species of various crop pests in the field constitute a complex of species with great taxonomic and ecological diversity. They may include predators or parasitoids, may be sucking or chewing, monophagous or polyphagous, univoltine or multivoltine living in/on soil or on plants, walking or flying, diurnal or nocturnal, and their range of phenology ensures the existence of active beneficials at any time during the growing season of crop(s). This diversity means that each species has in principle a different reaction and/or exposure to pesticides, which makes the selection of representative species a complicated process. Species selection can be further complicated by intraspecific variability in natural enemy responses to pesticides (Rosenheim and Hoy, 1986; Vidal and Kreiter, 1995).

The number of beneficial species to be tested with each pesticide ought to differ according to the crops where the pesticide is to be used. A total number of four to six beneficial species for each pesticide has often been suggested. The choice of beneficials for the test, taking account of their common use in practice, could be made with the aid of the following suggested key by Hassan (1983), although not all of the important pests and beneficial species are given below:

a) Crops with aphids as pests: at least 1 aphid predator (i.e., Chrysopidae, Coccinellidae, Syrphidae) as well as at least 1 aphid parasitoid (i.e., Aphidiinae).

b) Crops with Lepidoptera as pests: at least 1 egg parasitoid (i.e., Trichogrammatidae) as well as 1 larval or pupal parasitoid (i.e., Tachinidae, Braconidae, Ichneumonidae).

c) Crops with mites as pests: at least 1 predator (i.e., Typhlodromus sp., Amblyseius sp., and/or Anthocoridae, for glasshouse crops, Phytoseiu- lus sp.).

d) Crops with psylla as pests: Anthocoridae.

e) Crops with flies as pests: at least 1 parasitoid (i.e., Cynipidae, Ichneumonidae).

f) When soil is treated: at least 1 predator (i.e., Carabidae, Staphylinidae) as well as 1 soil living parasitoid (i.e., Cynipidae, Ichneumonidae).

g) Glasshouse crops with whiteflies as pests: the parasitoid Encarsia formosa.

\section{TESTING PRINCIPLES AND METHODOL- OGY}

At the initiative of FAO and in cooperation with international agencies, guidelines for the import and utilization of biological control agents were developed (FAO, 1992). The Working Group "Pesticides and Beneficial Organisms" of the International Organization for Biological Control and Integrated Control of Noxious Animals and Plants/ West Palaearctic Regional Section (IOBC/WPRS) has developed more than 30 laboratory methods in which a decline in beneficial capacity such as feeding or parasitic or predatory activity is investigated in addition to mortality. The carabid test is one well-known example of the tests with beneficial insects (Heimbach, 1992). Carabid of the species Poecilus cupreus on quartz sand are sprayed with the pesticide, after which insects are monitored for two weeks with regard to mortality and changes in behavior and feeding capacity. All IOBC/WPRS procedures are explicitly tied into a three-tier test scheme. This set of rules and regulations is intended to globally ensure that just like pesticides, beneficial species of crop pests do not induce any adverse ecotoxicological effects. The selection of the appropriate laboratory and further testing in semi-field or field tests is specified in a very complex flow scheme procedure (Felton et al., 1986).

The principles for testing are derived from a wish to advise commercial growers so that they may choose the pesticides with the least effects on the beneficial fauna. In practice, these pesticides must be ranked according to their effects on beneficials. Therefore, it is possible to compare results obtained in different countries under similar environmental conditions (Hassan, 1989; Samsøe-Petersen, 1990). A complete picture of temporal and spatial dynamics of pesticide effects on beneficial organisms is illustrated in Fig. 1. Although this 


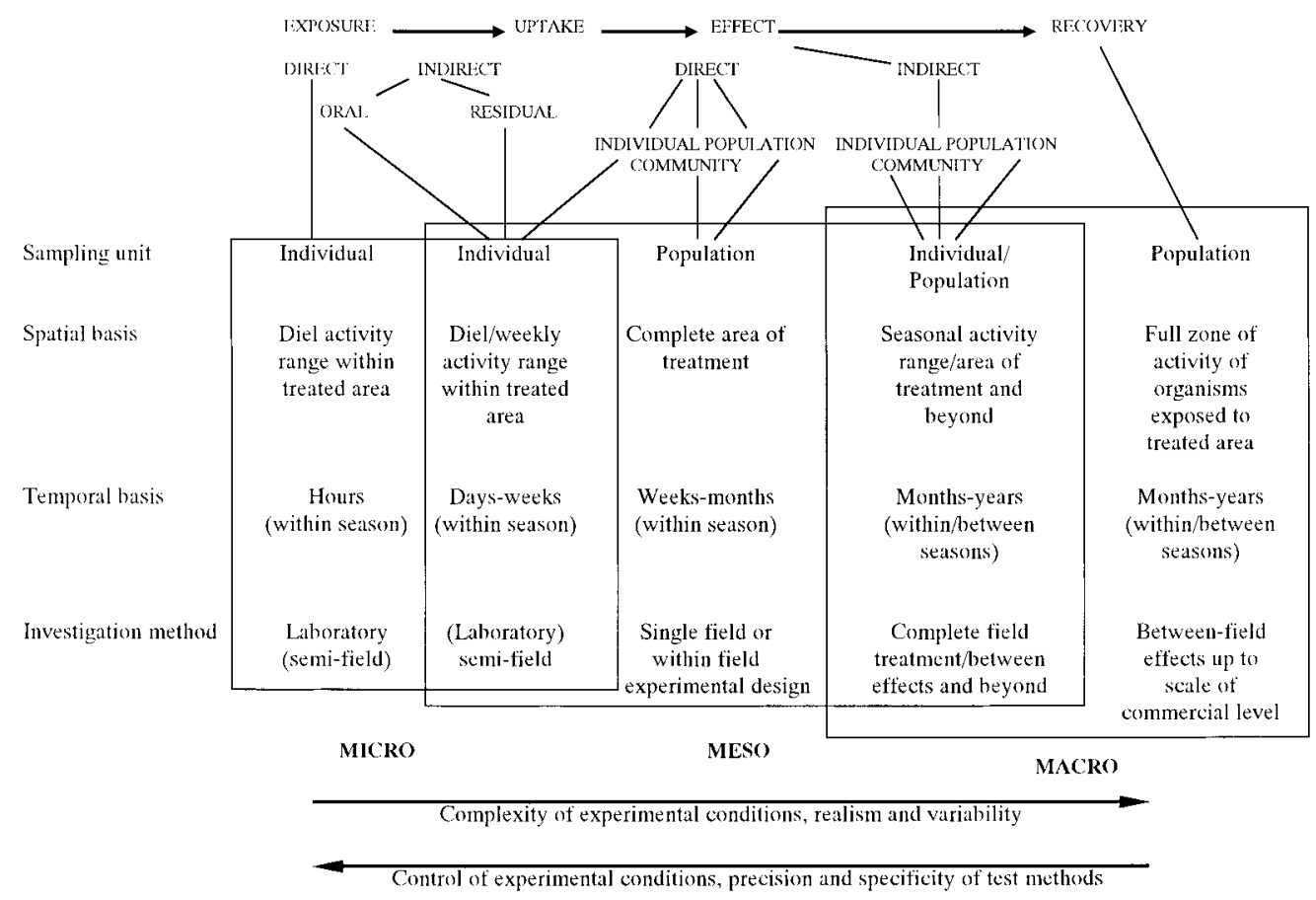

Fig. 1. Temporal and spatial dynamics of pesticide effects on beneficials (modified from Jepson, 1989).

typical scheme is complex, it presents the whole process of testing at micro (laboratory), meso (semi-field) and macro (field) levels. Consequently, the exposure, uptake, effect and recovery could be observed at individual and population bases.

The slide dip assay (FAO, 1984) has been the principal method used to test the acute effects of pesticides on predaceous mites and has provided a standard comparison of other assays. Unlike the methods in which a pesticide is topically applied or contacted as a residue on a treated surface, the slide dip is unsuitable for selection projects because mites are glued down and survivors are incapable of reproduction. Procedure and protocols of slide and petri dish assays for measuring resistance to permethrin in Amblyseius fallacis and selection of permethrin resistance were investigated and compared in detail (Thistlewood et al., 1992, 1995). In France, Malezieux et al. (1992) investigated the toxicity of a number of insecticides, acaricides and fungicides against $P$. persimilis under laboratory and field conditions. The methods developed allow determination of the residual toxicity of individual pesticide in practical situations. Spatial distribution of predatory and pest mites was investigated by using traditional practices under field conditions for a number of pesticides (Smith and Papacek, 1991; Li et al., 1992). The application of pesticides in the field presents real effects of the products used and their impacts on the population and community levels. Overmeer (1985) described a number of toxicological methods and also indicated each method's advantages and disadvantages for the important predaceous mites.

Sequential testing schemes for a number of beneficial mite and insect species were devised in the past for P. persimilis (Oomen et al., 1991), Apis mellifera (Oomen, 1986) and Encarsia formosa (Oomen et al., 1994). The testing scheme for $P$. persimilis is based on the question/test and decision-making from laboratory to field tests, and most of its criteria for evaluation of a product are based on IOBC/WPRS hazard classification (Hassan, 1994). The need for further testing or product selectivity could be investigated by this scheme for a number of other major predaceous mites (Fig. 2).

\section{TECHNICAL ASPECTS INVOLVED IN TESTING}

In recognition of the fact that no single testing method could provide sufficient information to assess the effects of pesticides on beneficials, a combination of tests that includes several laboratory as 
well as semi-field and field conditions are recommended.

Pesticides found to be selective to a particular

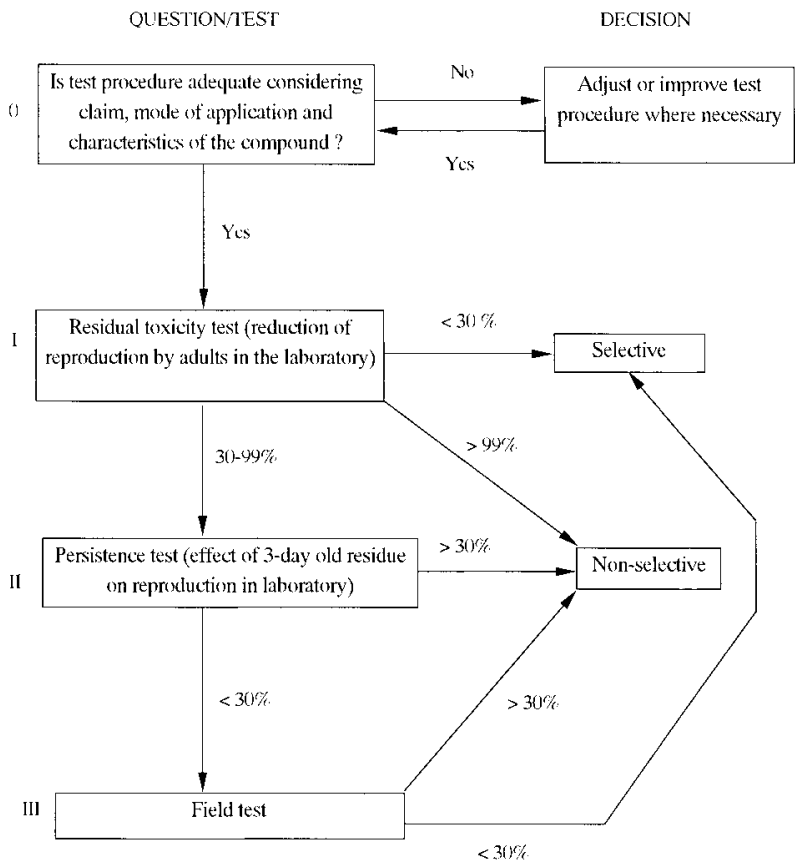

Fig. 2. Sequential decision making and testing scheme to evaluate effects of pesticides on Phytoseiulus persimilis in laboratory and field conditions (modified from Oomen et al., 1991). beneficial species in the laboratory test are most likely to be selective for the same species in the field, and usually no further testing in semi-field or field conditions is therefore recommended. However, further testing is recommended when a pesticide is found to be harmful in the initial toxicity test. A test to determine the duration of the harmful activity, a semi-field test to find out the effect of a dry pesticide film on plant or soil, or a field test to show the effect of pesticide on plants or soil inhabited by beneficial species should be carried out (Hassan, 1994).

Laboratory tests have obvious practical advantages, especially when study is urgently needed for a large number of pesticides. If only because of their simplicity, these tests are essential at least as a screening step (Klein et al., 1992). However, procedures and protocols in laboratory tests must fulfill certain criteria: the procedure used in the test should, for the most part, be standardized, their results should be reproduced and replicated, results should be easy to manage for statistics, comparative data should be available for the evaluation of test results and test(s) should be practicable.

Testing pesticide effects in the laboratory is a cost-effective tool for quantification of the toxicity to a range of species on a relevant substrate in field

Table 1. Extrapolation of pesticide testing results and inherent uncertainties in laboratory and field ${ }^{\mathrm{a}}$

Source of data Uncertainties

Laboratory conditions (Single species)
The influences of physical environmental conditions on the relationship between dose and response and the exposure regime are not taken into consideration.

A particular life stage in the life cycle is selected as being representative of the whole cycle. A few species, which are easy to breed and control are selected as representative of a large number of species in the environment.

Interaction with other species is not considered.

Effects at the individual level are applied to the population level without taking compensating mechanisms or behavioral adjustments into account.
Field conditions (Species complex)
A specific crop ecosystem is assumed to be representative of a general crop ecosystem. The stress triggered by the tested pesticides is assumed to be representative of the stress from non-tested pesticides.

Effects of specific climatic and physical environmental conditions and historical events on the behavior of the ecosystem and insufficient replicates may cause erroneous outputs. Difficulties of gathering data yielded by the dose-response relationship on the ecosystem may be faced.

Experimental period in relation to the time required for the ecosystem to manifest an adequate reaction and recover from the interventions may delay its significant role. Effects based on the uneven distribution of the organisms in the field in large ecosystems may limit its application.

\footnotetext{
${ }^{a}$ Modified from Römbke and Moltmann (1996).
} 
conditions. These tests may be designed to answer specific questions concerning the relative toxicity of parts of sprayed crop canopy, relative susceptibilities of species, the toxicity of different pesticides and the persistence of the toxic effects. Extrapolation of pesticide results recorded in laboratory and field conditions may face certain uncertainties if not planned clearly and objectively prior to testing (Table 1). However, great care must be taken if the results of tests are to be extrapolated to the field. Results may not be reflected under actual field conditions because they may sometimes overestimate mortality of organisms by the residues. For example, cypermethrin has an intrinsically high toxicity to honeybees, but in the field its toxicity is not realized because of repellency (Delabie et al., 1985). However, they may aid the interpretation of field trials (Unal and Jepson, 1991) and short-term effects of pesticides on a given species could be predicted in developing IPM strategies, for example, determining optimum dose-rates (Jepson et al., 1990).

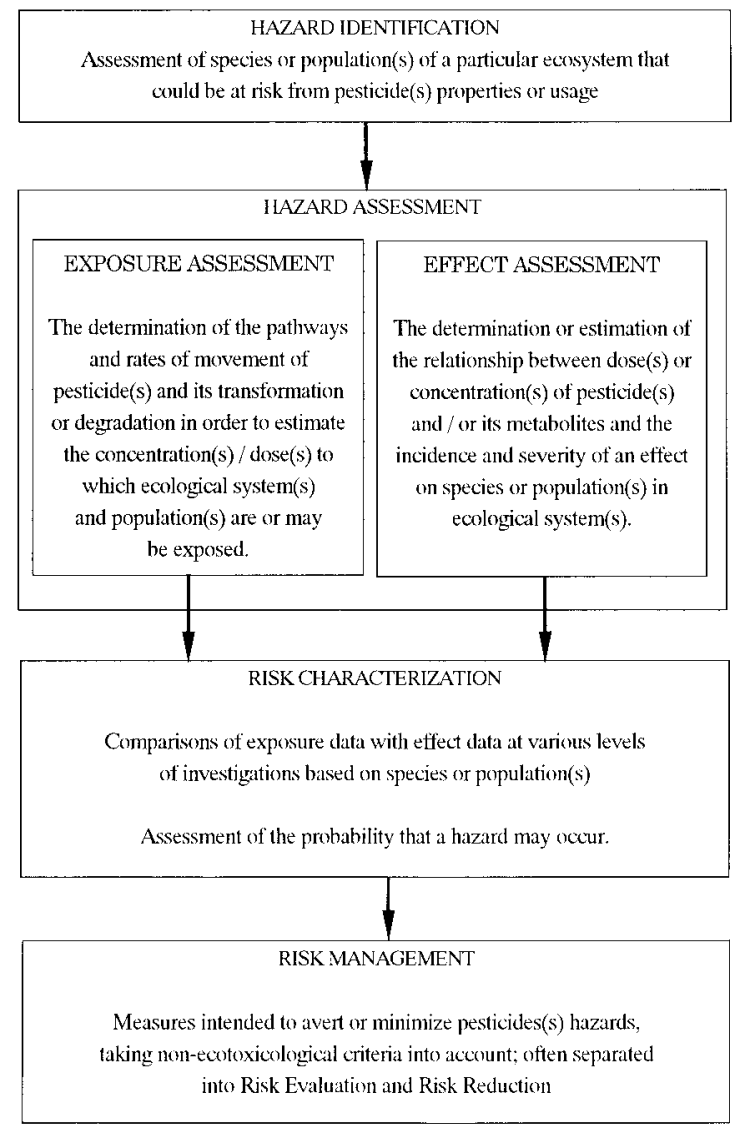

Fig. 3. Summary of the risk and hazard assessment process (modified from Römbke and Moltmann, 1996).
The Environmental Protection Agency reported a unique procedure to be adopted for the identification and management of risks associated with chemicals or their compounds in the environment (Römbke and Moltmann, 1996). The procedure deals with hazard identification, its assessment, risk characterization and its management (Fig. 3). To understand the effects of pesticides on ecosystems, it is necessary to examine a spectrum of effects from lethality to subtle changes in reproduction, beneficial performance, behavior, and vital organ physiology (Brown et al., 1992). A number of potential assessment and measurement endpoints are usually considered prior to pesticide testing at individual, population, community and ecosystem levels (Table 2). In this respect the acute toxicity (mortality) and chronic toxicity (growth, reproduction, juvenile development, morphological effects, biochemical or physiological effects, behavioral changes, teratogenity, mutagenity and car-

Table 2. Potential assessment and measurement endpoint used in pesticide testing in laboratory ${ }^{\mathrm{a}}$

\begin{tabular}{ll}
\hline \multicolumn{1}{c}{ Assessment endpoint } & Measurement endpoint \\
\hline $\begin{array}{c}\text { Individual } \\
\text { Generally not used in } \\
\text { ecotoxicological }\end{array}$ & Death \\
assessment except in & Growth \\
limited cases, e.g. with & Fecundity \\
rare or endangered & Overt symptomology \\
species & Biomarkers \\
Population & Tissue concentrations \\
Extinction & \\
Abundance & Occurrence \\
Yield/production & Abundance \\
Age/size class structures & Yield/production \\
Massive mortality & Age/size class structures \\
& Frequency of mass mortality \\
& Frequency of mass morbidity \\
Community & Reproduction \\
Market value & \\
Recreational value & Number of species \\
Usefulness/desired type & Species evenness/dominance \\
& Species diversity \\
Productive quality & Pollution indices \\
Productivity & Community quality indices \\
a & Community type \\
& Biomass \\
& Nutrient dynamics \\
& \\
& \\
&
\end{tabular}


Table 3. Major toxicity parameters involved in pesticide testing in laboratory ${ }^{a}$

\begin{tabular}{cl}
\hline \multicolumn{1}{c}{ Parameter } & \multicolumn{1}{c}{ Description } \\
\hline $\begin{array}{c}\text { Acute toxicity } \\
\text { Mortality }\end{array}$ & $\begin{array}{l}\text { Number of dead individuals } \\
\text { Corresponds to immobility in } \\
\text { some invertebrates }\end{array}$ \\
Chronic toxicity & \\
Growth & $\begin{array}{l}\text { Changes in biomass or body } \\
\text { length during the test, measured } \\
\text { in relation to the control or to } \\
\text { the starting value }\end{array}$ \\
Indicated differently, depending \\
on type, e.g. number of eggs or \\
immature animals, clutch size or \\
hatching rate
\end{tabular}

${ }^{a}$ Modified from Römbke and Moltmann (1996).

cinogenity parameters) could be observed under laboratory conditions (Table 3 ).

A pesticide is considered to be selective when it is more toxic to a pest than to a beneficial species. Selectivity can be expressed in both physiological and ecological terms (Pickett, 1988). Physiological selectivity resulting from differences in uptake, detoxification process and excretion that exist between different arthropod species is rarely recognized in IPM. Ecological selectivity is more complicated because it arises through differences in exposure to pesticides, with the beneficial species being exposed to less pesticide per individual than the pest species. Ecological selectivity may result from differences in behavior and biology or be a function of pesticide distribution, spray timing, differences in bioavailability achieved by formulation or physiochemical properties (Croft, 1990).

\section{EVALUATION AND INTERPRETATION OF RESULTS}

Evaluating the effects of pesticides on beneficial mite and insect species in pest management has historically concentrated on assessments of mortality, despite early recognition of the existence of sublethal effects on these organisms. Sublethal effects, which alter the ability of these beneficials to regulate the density of their prey or host ultimately affecting their long-term survival within the agroecosystem are of particular concern. The efficacy of natural enemies may be reduced by changes in their intrinsic rate of increase through effects on development rate, fecundity, longevity and sex ratio and by changes in their feeding behavior, host foraging efficiency and dispersal. Changes in performance of beneficials are more sensitive indicators of pesticide effects than measure of mortality alone (Franz, 1974). Morphological, biochemical or physiological effects and behavioral changes may occur in both acute and chronic tests and are generally difficult to quantify or evaluate statistically (Table 3 ). In addition, topical assays are often used because of ease in managing dosages, but these are not necessarily valid predictors of field results (Stark et al., 1995). Evaluating pesticide selectivity to beneficials is further complicated in systems where the beneficials complex is large and diverse and where multiple species play important roles. Screening pesticides against such complexes is a challenging but daunting task.

In the past, selectivity ratios of $\left(\mathrm{LD}_{50}\right.$ of a beneficial species $) /\left(\mathrm{LD}_{50}\right.$ of a pest species $)$ based on topical data have been considered sufficient to make decisions about the use of pesticides in crop protection. Although physiological selectivity is theoretically important (but rarely considered in IPM) (Graham-Bryce, 1987; Croft, 1990; Pfeiffer, 2000), extrapolating topical toxicity data to field effects may not be as straightforward as it may seem (Stark et al., 1995). A hazard ratio for beneficial mites and insect species, which determines the toxic dose per unit area may be more useful in this 
respect (Smart and Stevenson, 1982) and it is expressed as:

Hazard ratio $=($ recommended field rate

$$
(\mathrm{g}[\mathrm{AI}] / \mathrm{ha})) / \mathrm{LD}_{50}(\mu \mathrm{g} / \text { pest species })
$$

In the United Kingdom, insecticides with hazard ratios to honeybees of smaller than 50 are considered harmless and 50-2,500 are slightly to moderately toxic; when the ratio exceeds 2,500 , the pesticide is considered dangerous (Felton et al., 1986).

Several factors must be considered when trying to predict the effects that a pesticide might cause in the field (termed "risk" by ecotoxicologists). Overmeer and Van Zon (1982) proposed a formula for estimating the "Total Effect" (E) of a pesticide on a population of predatory mites (may also be used to evaluate pesticide effects on certain beneficial insect species). This took into account both direct effects (i.e., mortality of adults) and indirect effects (i.e., reduced fecundity), as explained below:

A value for corrected mortality $(M \%)$ is derived using Abbott formula (Abbott, 1925) (1),

$$
M=\left(M_{\mathrm{t}}-M_{\mathrm{c}}\right) /\left(100-M_{\mathrm{c}}\right) \times 100
$$

where $M_{\mathrm{t}}$ is the percentage mortality of the treated group and $M_{\mathrm{c}}$ is the percentage mortality of the control group.

A value for the treatment effects on the reproductive capacity $(R)$ of the test organism is derived from formula (2),

$$
R=R_{\mathrm{t}} / R_{\mathrm{c}}
$$

where $R_{\mathrm{t}}$ is the average number of eggs produced per treated female survivor in the treated group and $R_{\mathrm{c}}$ is the average number of eggs produced per female of the control group.

The overall treatment effect (i.e., the reduction in beneficial capacity) is calculated from formula (3),

$$
E=100 \%-(100 \%-M) \times R
$$

This formula was further elaborated by Angeli et al. (1997), to ascertain female mortality and fecundity as well as egg fertility and neonatal mortality. The formula may be expressed as:

$$
\begin{aligned}
E= & 100 \%-(100 \%-M) \times R_{1} \times\left(1-R_{2} / 100\right) \\
& \times\left(1-R_{3} / 100\right)
\end{aligned}
$$

where $R_{1}$ is the ratio of the number of eggs in the
Table 4. IOBC/WPRS hazard assessment classes based on the total effects of pesticides

\begin{tabular}{lc}
\hline \multicolumn{1}{c}{ Categories } & $\%$ Mortality/RBC $\mathrm{RB}^{\mathrm{a}}$ \\
\hline Laboratory & $<30$ \\
Not harmful & $30-79$ \\
Slightly harmful & $80-99$ \\
Moderately harmful & $>99$ \\
Seriously harmful & \\
Semi-field (persistent activity) & $<5$ days \\
Short lived & $5-15$ days \\
Slightly persistent & $16-30$ days \\
Moderately persistent & $>30$ days \\
Persistent & \\
Semi-field and field & $<25$ \\
Not harmful & $25-50$ \\
Slightly harmful & $51-75$ \\
Moderately harmful & $>75$ \\
Seriously harmful &
\end{tabular}

${ }^{\text {a }}$ Reduction in beneficial capacity.

treated sample to that in the control, $R_{2}$ is the $\%$ hatched eggs and $R_{3}$ is the \% mortality of early instars.

The Working Group of IOBC/WPRS (Hassan, $1992,1994)$ recommends that the values for total effects should be categorized according to the pesticide effects under laboratory, semi-field and field conditions (Table 4). Certain modifications of such hazard classifications are, however, needed, especially in the following categories: i) number of classes may be reduced since experience has shown that the variability of the results obtained with carabid tests renders the use of so many classes impracticable; ii) definition of individual classes may be changed since harmful effects may indeed exist below an effect of $100 \%$; iii) the categorization offers no indication of the dose-response relationship. Furthermore, pesticide legislation in most countries has emphasized testing on honeybees, silkworms, fish, some mammals and birds etc., and has had little regard for beneficial mite and insect species. Consequently, the results are evaluated based on the survival of organisms in treated and untreated groups (Table 5). In crop protection, however, beneficial mite and insect species are frequently exposed to various pesticides because of their close association with the prey and host (pests). Studying only the lethal effects of pesticides may not completely achieve the targets, be- 
Table 5. Evaluation and interpretation of effects of acute toxicity at fixed dose levels ${ }^{\text {a }}$

\begin{tabular}{|c|c|c|}
\hline $\begin{array}{c}\text { Dose } \\
\left(\mathrm{mg} \mathrm{kg}^{-1}\right. \\
\text { body weight) }\end{array}$ & $\begin{array}{l}\text { Results based } \\
\text { on survival }\end{array}$ & $\begin{array}{l}\text { Interpretation based } \\
\text { on compounds }\end{array}$ \\
\hline \multirow[t]{3}{*}{5} & $<100 \%$ & VERY TOXIC \\
\hline & $\begin{array}{l}100 \% \text { : but } \\
\text { evident toxicity }\end{array}$ & TOXIC \\
\hline & $\begin{array}{l}\text { 100\%: no } \\
\text { evident toxicity }\end{array}$ & Compare at $50 \mathrm{mg} \mathrm{kg}^{-1}$ \\
\hline \multirow[t]{3}{*}{50} & $<100 \%$ & $\begin{array}{l}\text { May be TOXIC/VERY TOXIC } \\
\text { Compare at } 5 \mathrm{mg} \mathrm{kg}^{-1}\end{array}$ \\
\hline & $\begin{array}{l}100 \% \text { : but } \\
\text { evident toxicity }\end{array}$ & Harmful \\
\hline & $\begin{array}{l}100 \% \text { : no } \\
\text { evident toxicity }\end{array}$ & Compare at $500 \mathrm{mg} \mathrm{kg}^{-1}$ \\
\hline \multirow[t]{3}{*}{500} & $<100 \%$ & $\begin{array}{l}\text { May be TOXIC/HARMFUL } \\
\text { Compare at } 50 \mathrm{mg} \mathrm{kg}^{-1}\end{array}$ \\
\hline & $\begin{array}{l}100 \% \text { : but } \\
\text { evident toxicity }\end{array}$ & No significant acute toxicity \\
\hline & $\begin{array}{l}\text { 100\%: no } \\
\text { evident toxicity }\end{array}$ & Compare at $2,000 \mathrm{mg} \mathrm{kg}^{-1}$ \\
\hline \multirow[t]{2}{*}{2,000} & $<100 \%$ & Compare at $500 \mathrm{mg} \mathrm{kg}^{-1}$ \\
\hline & $\begin{array}{l}100 \% \text { : with or } \\
\text { without evident } \\
\text { toxicity }\end{array}$ & No significant acute toxicity \\
\hline
\end{tabular}

${ }^{\text {a }}$ Modified from Richardson (1996).

cause sublethal effects of pesticides on these organisms may not be sustainable for crop protection if not investigated and evaluated properly (Bakker et al., 1992; Haseeb et al., 2000a, b).

There is a deficit of basic knowledge on pesticide testing, appropriate ecotoxicological methods and the corresponding assessment criteria in most of developing countries. In advanced countries, a tiered test program, ranging from pre-registration laboratory tests all the way up to field monitoring of usage, should form the foundation for the definition of ecotoxicological measures. Moreover, focus has to be placed on assessing the changed exposure situation (Fig. 4). In other words, the objective must be to adapt the methods and concepts in the industrialized countries to the special conditions in the Third World, such as poor quality modes of application due to limited financial and personnel resources (Römbke and Moltmann, 1996). Furthermore, regional differences originating from climatic conditions and ecosystem must be taken into consideration for each situation.
TOXICITY

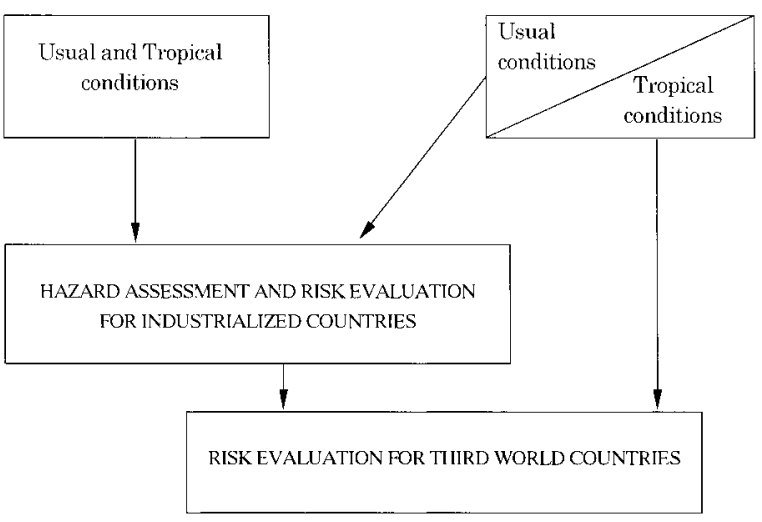

Fig. 4. Evaluation of risks posed by pesticides in the Third World with consideration of specific exposure conditions (modified from Römbke and Moltmann, 1996).

\section{IMPLICATIONS OF PESTICIDE EFFECTS IN IPM}

Use of selective pesticides is the first prerequisite for a sound IPM in any crop production. Without pesticide testing on beneficial mites and insect species, the selectivity, risks and hazards associated with the needed pesticides in pest management cannot be determined. Pesticides, which are selective against the beneficial mite and insect species but are important for pest control, will always play a useful role in IPM programs.

Approaches to management of various crop pests in crop protection have evolved over time. During the last three decades, IPM has been confirmed as a valid approach for addressing and solving pest problems in crops. It emerged as the strategy for pest control as a result of the significant change in attitude promoted by the excessive use of persistent pesticides during the 1950-1960s in Europe and USA and almost a decade later in South Asian countries (Baloch and Haseeb, 1996). Initially IPM employed optimal combinations of biological, physical and chemical tactics for pest control, which has to be integrated into a harmonious strategy designed to provide durable and sustainable crop protection. It represented a complete change in the philosophy of pest control from pest eradication towards pest management. Oomen (1992) discussed the critical relationship of biocontrol and chemical control in pest management. Pest control through pesticides has both desired (efficacy) and undesired effects, depending on the con- 
ditions under which the crop protection measures were undertaken.

Parallel to these moves to reduce pesticide use, there have been considerable efforts to develop national strategies that actively foster the adoption of integrated management practices. Such practices are called IPM programs in the United States, Japan, other Asian countries and Australasia or integrated crop management (ICM) programs and integrated farming systems (IFS) in Europe. The world's agrochemical industries are also embracing the notion of IPM. The promotion of IPM by multinational companies is a sign of the changing era in crop protection, although certain analysts have considered that it may reflect the concept of pesticide itself more than pest management. Global Crop Protection Federation also uses the same definition of IPM given in the FAO's International Code of Conduct on the Distribution and Use of Pesticides (GCPF, 1997). We are optimistic about this approach and hope that the industry(s) will further augment its role in producing and marketing those pesticides which may pose no or negligible risks to beneficial species. We appreciate that this will further strengthen sustainable IPM programs worldwide.

\section{FUTURE PROSPECTS}

To protect losses of crops due to various pests, pesticides are usually applied worldwide. Beneficial mite and insect species live together with their prey or hosts and the probability of pesticide risks to these beneficials appears to be high as compared with honeybees, silkworms, fish, some mammals, birds, etc. Research and development (R\&D) in the area of pesticide testing on beneficial mite and insect species is still in its infancy in a number of countries, especially developing countries. Awareness of environment-friendly products and processes are increasingly being adopted in certain advanced countries; and developing countries should realize to initiate similar procedures if they are to trade in international markets.

Pesticides will still be required to control key pests of crops and their application leads to more intense use in crop protection in the near future. Although, even if, for some reason, total pesticide usage is significantly reduced, the possibility that pesticides will continue to deplete either beneficial species or their beneficial performance will remain a grave concern. Therefore, their potential risks to beneficial mite and insect species must not be balanced merely against marketable crop yields. We clearly need to protect these beneficial organisms. This can be achieved by using proper research and development to ensure that the adverse effects of non-selective pesticides do not increase.

Most advanced countries have adequate infrastructure to promote research on the effects of pesticides on beneficial mite and insect species including institutional capabilities, skilled manpower and financial resources, which enables them to assess, monitor and even enforce their toxic chemical laws and policies. The assistance of international cooperation led to the initiation of the same research work on beneficial mite and insect species in some developing countries simultaneously. However, in many developing countries it is still a new phenomenon. Most developing countries do not have basic legislative framework or an administrative infrastructure that can manage the implications of pesticidal effects in IPM. Moreover, the skilled human and financial resources as well as an institutional framework including analytical laboratories, field research, monitoring and regulatory agencies and law enforcement and availability to rapidly evolving information on pesticidal effects on beneficial mite and insect species are not readily available to most developing countries.

Pesticide regulatory processes would be greatly facilitated by improved information, increased clarity and more consistent policies. Risk standards need to be clarified and applied consistently with scientifically sound risk assessment methodologies and logical consistent assumptions. More research and field-testing efforts should be invested in developing actual persistent data and pesticide dissipation curves under known conditions of field use, in each major climatic region within which a given crop is produced. Therefore, more timely, accurate data are needed on actual pesticide use patterns viz., number of applications, rate of applications, and preharvest intervals. Special efforts should be targeted to newly introduced pesticides, for use with unusual pest problems and for new cropping patterns. For pesticides not currently detectable, new low-cost and practical methods should be developed with special emphasis on widely used pesticides. We believe that all these steps are urgently 
needed to devise sustainable IPM strategies to control crop(s) pests worldwide.

\section{REFERENCES}

Abbott, W. S. (1925) A method of computing the effectiveness of an insecticide. J. Econ. Entomol. 18: 265-267.

Angeli, G., D. Forti and R. Maines (1997) Toxicity of a number of pesticides on mortality and reproduction of the predatory mite Amblyseius andersoni Chant (Acari: Phytoseiidae). In New Studies in Ecotoxicology (P. T. Haskell and P. K. M. Ewen eds.). The Welsh Pest Management Forum, Univ. Wales, Cardiff, pp. 1-4.

Bakker, F., A. Grove, S. Blumel, J. Calis and P. Oomen (1992) Side effect tests for phytoseiids and their rearing methods. Bull. IOBC/WPRS 15: 61-75.

Baloch, U. K. and M. Haseeb (1996) Persistent pesticide pollutants in crop protection. In Risk Reduction, Chemicals and Energy into the 21st Century (M. L. Richardson ed.). Taylor and Francis, London, pp. 329-343.

Brown, T., C. Hagedorn, A. Johnels, G. Lacy, V. Landa, D. Peakall, D. Pimentel, T. Soldan and J. Veleminsky (1992) Methods to assess toxic effects on ecosystems. In Methods to Assess Adverse Effects of Pesticides on Non-Target Organisms (R. G. Tardiff ed.). John Wiley and Sons, Chichester, pp. 65-76.

Croft, B. A. (1990) Arthropod Biological Control Agents and Pesticides. Wiley Interscience, New York. 723 pp.

Delabie, J., C. Bas, C. Fonta and C. Masson (1985) Toxic and repellent effects of cypermethrin on the honeybee. Laboratory, glasshouse and field experiments. Pesticide Sci.16: 409-415.

FAO (Food and Agriculture Organization) (1984) Recommended methods for the detection and measurement of resistance of agricultural pests to pesticides. Methods for phytoseiid predatory mites. FAO Plant Prot. Bull. 32: 25-27.

FAO (1992) Draft code for the import and release of biological control agents. Meeting report AGP/1992/M/3 of the expert consultation on guidelines for the introduction of biological control agents. Rome, Italy. $21 \mathrm{pp}$.

Felton, J. C., P. A. Oomen and J. H. Stevenson (1986) Toxicity and hazard of pesticides to honey bees: harmonization of test methods. Bee World 67: 114-124.

Franz, J. M. (1974) Testing of side-effects of pesticides on beneficial arthropods in the laboratory-a review. $Z$. Pflkrankh. Pflschutz. 81: 141-174.

GCPF (Global Crop Protection Federation) (1997) IPM-Integrated Pest Management-The Way Forward for the Crop Protection Industry. Brussels, Belgium. 21 pp.

Graham-Bryce, I. J. (1987) Chemical methods. In Integrated Pest Management (A. J. Burn, T. H. Coaker and P. C. Jepson eds.). Academic Press, London, pp. 113-159.

Haseeb, M., H. Amano and H. Nemoto (2000a) Pesticidal effects on mortality and parasitism rates of Diadegma semiclausum (Hellén), a parasitoid of the diamondback moth. BioControl 45: 165-178.

Haseeb, M., H. Amano and H. Nemoto (2000b) Effects of pesticides on the mortality and beneficial capacity of $\mathrm{Di}$ - adegma semiclausum (Hymenoptera: Ichneumonidae), a primary parasitoid of the diamondback moth. Bull. IOBC/WPRS 23: 39-48.

Hassan, S. A. (1983) Procedure for testing the side effects of pesticides on beneficial arthropods as being considered by the International Working Group "Pesticides and Beneficial Arthropods." Mitt. Dtsch. Ges. Allg. Angew. Entomol. 4: 85-88.

Hassan, S. A. (1989) Testing methodology and concepts of the IOBC/WPRS working group. In Pesticides and Non-Target Invertebrates (P. C. Jepson ed.). Intercept, Dorset, pp. $1-18$.

Hassan, S. A. (1992) Guidelines for testing the effects of pesticides on beneficial organisms. Descriptions of test methods. Bull. IOBC/WPRS 15: 18-39.

Hassan, S. A. (1994) Activities of the IOBC/WPRS working group "Pesticides and Beneficial Organisms." Bull. IOBC/WPRS 17: 1-5.

Heimbach, U. (1992) Standard laboratory method to test effects of pesticides on Poecilus cupreus (Coleoptera, Carabidae). Proc. Intl. Symp. Ecotoxicology. GSF-Ber. 1/92: 105-109.

Hull, L. A. and E. H. Beers (1985) Ecological selectivity: Modifying chemical control practices to preserve natural enemies. In Biological Control in Agricultural IPM Systems (M. A. Hoy and D. C. Herzog eds.). Academic Press, New York, pp. 103-122.

Jepson, P. C. (1989) The temporal and spatial dynamics of pesticide side-effects on non-target invertebrates. In Pesticides and Non-Target Invertebrates (P. C. Jepson ed.). Intercept, Dorset, pp. 97-127.

Jepson, P. C., S. J. Duffield, J. R. M. Thacker, C. F. G. Thomas and J. A. Wiles (1990) Predicting the side-effects of pesticides on beneficial invertebrates. Proceedings of the British Crop Protection Conference, Brighton 3: 957962.

Kapustka, L. A. and M. Reporter (1993) Terrestrial primary producers. In Handbook of Ecotoxicology (P. Calow ed.). Blackwell Scientific Publ., Oxford, pp. 278-298.

Klein, A. W., P. Apel and J. Goedicke (1992) UBA-principles on criteria and procedures for environment assessment of pesticides. Chemosphere 24: 793-815.

Li, S. Y., R. Harmsen and H. M. A. Thistlewood (1992) The effect of pyrethroids lambdacyhalothrin applications on the spatial distribution of phytophagous and predatory mites in apple. Exp. Appl. Acarol. 15: 259-269.

Lim, G. S., A. Sivapragasam and M. Ruwaida (1986) Impact assessment of Apanteles plutellae on diamondback moth using an insecticide-check method. In Diamondback Moth Management (N. S. Talekar and T. D. Griggs eds.). AVRDC, Tainan, pp. 423-436.

Malezieux, S., L. Lapchin, M. Pralavorio, J. C. Moulin and D. Fournier (1992) Toxicity of pesticides residues to a beneficial arthropod, Phytoseiulus persimilis (Acari: Phytoseiidae). J. Econ. Entomol. 85: 2077-2081.

Midgarden, D., S. J. Fleischer, R. Weisz and Z. Smilowitz (1997) Site-specific integrated pest management of esfenvalerate resistance in Colorado potato beetle (Coleoptera: Chrysomelidae) and on densities of natural enemies. $J$. 
Econ. Entomol. 90: 855-867.

Oomen, P. A. (1986) A sequential scheme for evaluating the hazard of pesticides to bees, Apis mellifera. Med. Landbouww. Rijksuniv. Gent. 51/3b: 1205-1213.

Oomen, P. A. (1992) Chemical in integrated control. Pest. Sci. 36: 349-353.

Oomen, P. A., J. A. Jobsen, G. Romein and G. L. Wiegers (1994) Side effects of 107 pesticides on the whitefly parasitoid Encarsia formosa studied and evaluated according to EPPO guideline no. 142. Bull. OEPP/EPPO 24: 89107.

Oomen, P. A., G. Romeijn and G. L. Wiegers (1991) Side effects of 100 pesticides on the predatory mite Phytoseiulus persimilis collected and evaluated according to the EPPO guidelines. Bull. OEPP/EPPO 21: 701-712.

Overmeer, W. P. J. (1985) Toxicological methods. In Spider Mites, Their Biology and Natural Enemies and Control (W. Helle and M. W. Sabelis eds.). Elsevier, Amsterdam, pp. 183-189.

Overmeer, W. P. J. and A. Q. Van Zon (1982) A standardized method for testing the side effects of pesticides on the predacious mite Amblyseius potentillae Garman (Acarina: Phytoseiidae). Entomophaga 27: 357-364.

Pfeiffer, D. G. (2000) Selective pesticides. In Integrated Pest Management Techniques for Environmental Protection (J. E. Rechcigl and N. A. Rechcigl eds.). CRC Press, Boca Raton, Florida, pp. 131-144.

Pickett, J. A. (1988) Integrating use of beneficial organisms with chemical crop protection. Philos. Trans. R. Soc. B 318: 203-209.

Poehling, H. M. (1989) Selective application strategies for insecticides in agricultural crops. In Pesticides and NonTarget Invertebrates (P. C. Jepson ed.). Intercept, Dorset, pp. 151-175.

Richardson, M. L. (1996) Prolog. In Risk Reduction Chemicals and Energy into the 21st Century (M. L. Richardson ed.). Taylor and Francis, London, pp. 3-12.

Römbke, J. and F. Moltmann (1996) Applied Ecotoxicology. CRC Press, Boca Raton, Florida. 282 pp.

Rosenheim, J. A. and M. A. Hoy (1986) Intraspecific variations in levels of pesticide resistance in field populations of a parasitoid Aphytis melinus (Hymenoptera: Aphelinidae), the role of pest selection pressures. J. Econ. Entomol. 79: 1161-1173.

Ruberson, J. R., H. Nemoto and Y. Hirose (1998) Pesticides and conservation of natural enemies in pest management. In Conservation Biological Control (P. A. Barbosa ed.). Academic Press, New York, pp. 207-220.

Samsøe-Petersen, L. S. (1990) Sequences of standard methods to test effects of chemicals on terrestrial arthropods. Eco. Environ. Saft. 19: 310-319.

Smart, L. E. and J. H. Stevenson (1982) Laboratory estimation of toxicity of pyrethroid insecticides to honey bees: relevance to hazard in the field. Bee World 63: 150-152.

Smith, D. and D. F. Papacek (1991) Studies of the predatory mite Amblyseius victoriensis (Acarina: Phytoseiidae) in citrus orchards in southeast Queensland: Control of Tegolophus australis and Phyllocoptruta oleivora (Acarina: Eriophyidae), effects of pesticides, alternative host plants and augmentative release. Exp. Appl. Acarol. 12: 195-217.

Soon, G. L. (1990) Overview of vegetable IPM in Asia. FAO Plant Protection Bulletin 38: 73-87.

Stark, J. D., P. C. Jepson and D. F. Mayer (1995) Limitation to use of topical toxicity data for prediction of pesticide side effects in the field. J. Econ. Entomol. 88: 1081-1088.

Sterk, G. (1993) Studies on the effects of pesticides on beneficial arthropods. Acta Horticulturae 347: 233-243.

Stevenson, J. H. and J. H. H. Walters (1983) Evaluation of pesticides for use with biological control. Agric. Ecosyst. Environ. 10: 81-101.

Suter, G. W. (1989) Ecological endpoints. In Ecological Assessment of Hazardous Waste Sites. A Field and Laboratory Reference (W. Warren-Hicks, B. R. Parkhurst and S. S. Baker eds.). Environmental Protection Agency, Corvallis, pp. 122-128.

Tabashnik, B. E. and B. A. Croft (1985) Evaluation of pesticide resistance in apple pests and their natural enemies. Entomophaga 30: 37-49.

Thistlewood, H. M. A., D. J. Pree and L. A. Crawford (1992) Comparison of slide dip and petri dish assays for measuring resistance to permethrin in Amblyseius fallacis (Acari: Phytoseiidae). J. Econ. Entomol. 85: 2051-2057.

Thistlewood, H. M. A., D. J. Pree and L. A. Crawford (1995) Selection and genetic resistance in Amblyseius fallacis (Garman) (Acari: Phytoseiidae) from Ontario apple orchards. Exp. Appl. Acarol. 19: 707-721.

Unal, G. and P. C. Jepson (1991) The toxicity of pesticide residues to beneficial invertebrates in cereal crops. Ann. Appl. Biol. 118: 493-502.

Vidal, C. and S. Kreiter (1995) Resistance to a range of insecticides in predaceous mite Typhlodromus pryi (Acari: Phytoseiidae): Inheritance and physiological mechanisms. J. Econ. Entomol. 88: 1097-1105.

Waage, J. (1996) Yes, but does it work in the field? The challenge of technology transfer in biological control. Entomophaga 41: 315-332. 